\title{
Geochemical conditions of hydrocarbon accumulation in low-permeability shale sequences
}

\author{
Vagif Kerimov $^{1}$, Rustam Mustaev ${ }^{1, *}$, Uliana Serikova ${ }^{1}$, and Javidan Ismailov ${ }^{2}$ \\ ${ }^{1}$ Russian State Geological Prospecting University, Department of geology and exploration of \\ hydrocarbon deposits, 23 Miklouho-Maclay, Moscow, Russia \\ ${ }^{2}$ Gubkin State University of Oil and Gas, 65 Leninsky Prospekt, Moscow, Russia
}

\begin{abstract}
The report is devoted to the study of conditions for the formation of organic porosity-void spaces of organic origin formed during transformation of the organic matter into hydrocarbons, and their role in the formation of hydrocarbon accumulation in low-permeability shale strata. The experience of studying and developing known shale formations of the world testifies to the fact that such strata are hybrid phenomena, that is, they are both oil- and gas-bearing strata containing traditional and nontraditional accumulations of hydrocarbons. Based on the results of the programmed pyrolysis by the Rock-Eval- 6 method, an estimate has been performed to quantify organic (kerogen) porosity. This estimate allows for determining the forecast retention volume of $\mathrm{HCs}$ generated during catagenesis.
\end{abstract}

\section{Introduction}

The purpose of this paper is to investigate the conditions for the formation of organic porosity and its role in the formation of hydrocarbon accumulations in low-permeability shale strata. According to classical concepts, the main function of oil and gas source rock is the generation of hydrocarbons (HC). However, it was recently revealed that oil and gas deposits are not only a source of $\mathrm{HC}$ formation but also a place of $\mathrm{HC}$ accumulation.

As examples of this phenomenon in the territory of Russia may be mentioned sequences of the Khadum and Bazhenov Formations and the Domanik horizon which are hybrid phenomena combining both conventional and unconventional hydrocarbon accumulations.

The Khadum Formation in the Maykopian series (the Oligocene - Lower Miocene deposits of the Paleogene system in the Cenozoic erathem) is broadly developed in the Caucasus territory (Fig. 1). The Caucasus Maykopian series kerogen containing shale sequences is represented by a number of compact multilayered pelite rocks (clay, marl, clayey limestone, argillite, siltstone and the shale proper) enclosing all possible forms of OM (organic matter) at various maturation stages [1-6]. For the purpose of studying the

*Corresponding author: r.mustaev@mail.ru 
filtration-capacity (permeability-porosity) properties of the Khadum Formation, thin section studies have been conducted by a raster electronic microscopy (REM) method.

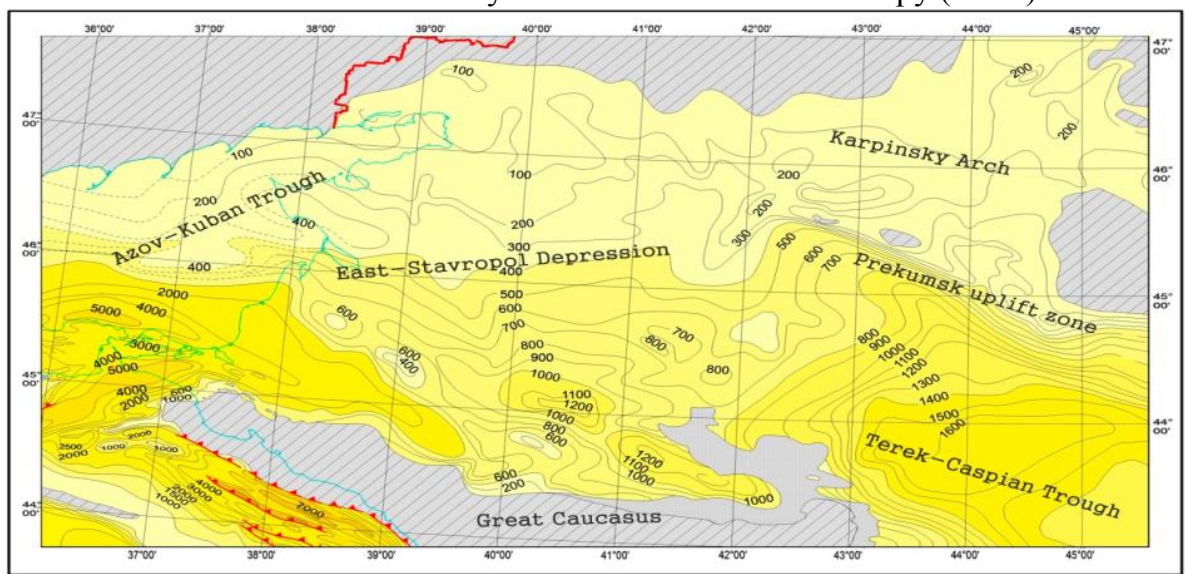

Fig. 1. Composite thickness map of the Maykopian sediments.

\section{The study technique}

Raster (scanning) electronic microscopy (REM or SEM) enables study of the micromorphology and subtle structure of the surface in various materials with help from a focused electron beam scanning the surface.

The Rock-Eval pyrolysis method was used for studying the organic matter $(\mathrm{OM})$ of the shale sequence. This is a method of direct determination of the spectrum of parameters reflecting qualitative and quantitative features of rock OM. The pyrolytic studies have been conducted using the Rock-Eval 6 analyzer by VINCI Technologies.

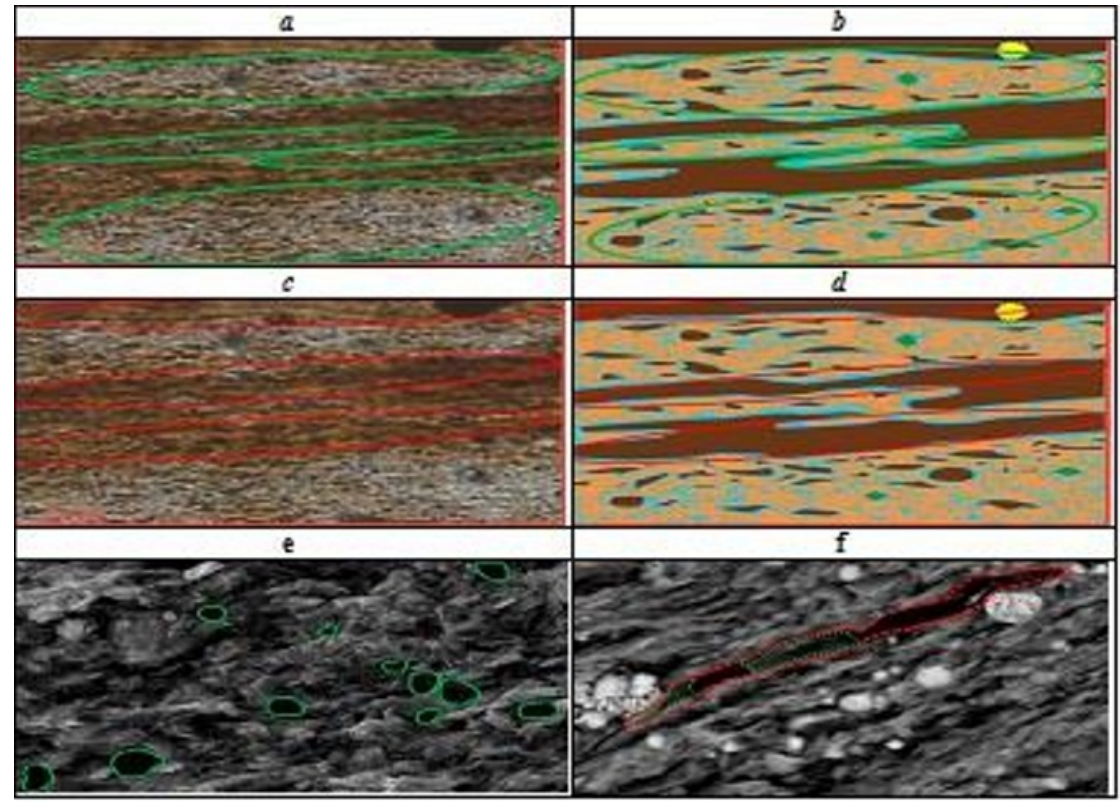

Fig. 2. Rock matrix voids and pores in the Khadum sequence: $a-b$ - inter-laminar and isometric. 


\section{Study results and discussion}

Using REM, samples have been studied from wells on Zhuravsk-Vorobyevsk, Praskoveysk, Achikulaksk, Anosovsk, Polevoy, Karanogaysk and South Ozek-Suatsk prospects as well as from wells drilled on the Stavropol Arch.

The void space structure study of both the Khadum Formation and Batalpashin horizon (Fig. 2) indicated that organic pores are peculiar centers, around which emerge slot-like, isometric pores and voids forming the secondary mineral and organic porosity and secondary fracturing. In these pores occurs a retention of hydrocarbons not only by the mineral part of the rock but also by its organic component, which has adsorption properties.

Based on the results of the pyrolytic analysis by the Rock-Eval-6 technique, a quantitative analysis has been conducted of the source rock organic porosity and the pore space influence on the generation and retention of the emerged hydrocarbons has been interpreted. The $\mathrm{S}_{1} / \mathrm{TOC}$ parameter has been used for characterizing the oil source rock sequence's productivity.

Hydrocarbon adsorption in the Khadum Formation is shown in Fig. 3. It indicates that an elevated appearance of adsorption effect is observed in the East Stavropol depression.

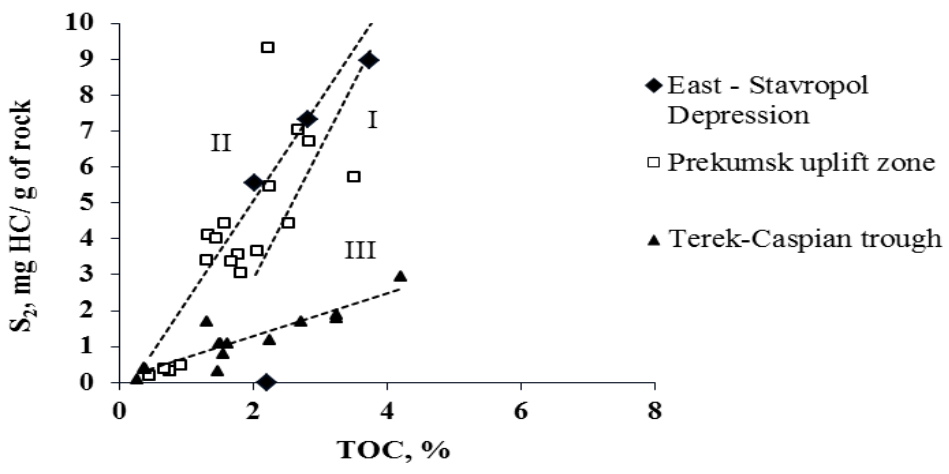

Fig. 3. Residual generation potential, $S_{2}$, vs. total organic carbon, TOC, value in horizons of wells IEast Stavropol depression, II-Kuma system of highs and III-Terek-Caspian trough. Approximation equations: I - $\mathrm{y}=3.6327 \mathrm{x}-4.3284$; II $-\mathrm{y}=2.8052 \mathrm{x}-0.5227$; III $-\mathrm{y}=0.5978 \mathrm{x}$.

Each hydrocarbon emission from the kerogen surface changes its porosity. For this reason, the balance method applied for evaluating the organic porosity is based on a simplified assumption that the size of the pore space is proportional to the $\mathrm{HC}$ volume leaving the kerogen surface.

Fig. 4 shows isocurves with the inclination angle tangent corresponding to the $\mathrm{S}_{2} / \mathrm{TOC}$ value. It allows separating the diagram area into zones corresponding with kerogen type.

Taking into account that TOC conversion in hydrocarbons runs according to the scheme: type I $-80 \%$, type II $-50 \%$, type III $-20 \%$, it is possible to identify the initial TOC value.

$\mathrm{TOC}_{0}=\mathrm{TOC}_{\text {measured }} /(1-$ conversion $\%)$

Thus, knowing the present-day OM content value in the source rock, hydrogen index, OM thermal maturity and $\mathrm{S}_{1}$ value, it is possible to estimate the initial TOC and HI values. For the determination of organic (kerogen) porosity from formulas, a determination is required of the initial parameters $\left(\mathrm{HI}_{0}, \mathrm{TOC}_{0}, \mathrm{GOC}_{0}\right)$ and $\mathrm{OM}$ thermal maturity. Two equations have been used for estimating the organic porosity (PO):

$>$ First - proposed by F. Chen, Sh. Lu and X. Ding [7],

$\mathrm{PO}_{1}=\mathrm{TOC}_{0} \cdot \mathrm{GOC} \cdot \mathrm{TR} \cdot \mathrm{k} \cdot \mathrm{D}_{1} / \mathrm{D}_{2}(\%)$.

$>$ Second - proposed by C. J. Modica, Scott G. Lapierre [8].

$\mathrm{PO}_{2}=\left[\left(\mathrm{TOC}_{0} \cdot \mathrm{HI}_{0} \bullet \mathrm{TR} \cdot \mathrm{k} \cdot \mathrm{D}_{1} / \mathrm{D}_{2}\right)\right] / 1000(\%)$. 


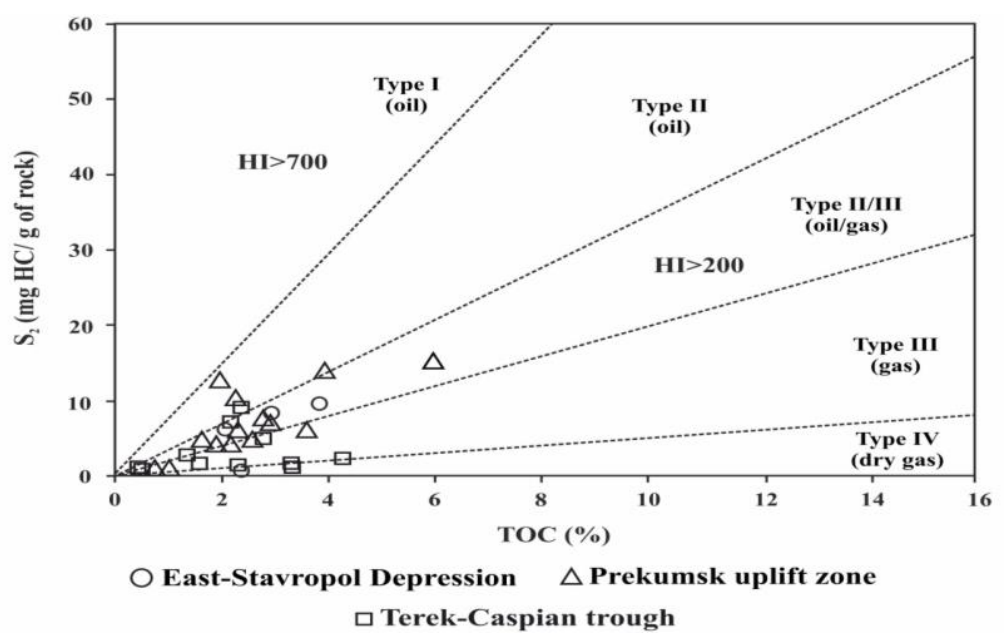

Fig. 4. Residual generation potential $S_{2}$ vs. measured organic carbon values TOC with isocurves of the initial hydrogen index $\mathrm{HI}_{0}$ values.

The estimation succession is as follows:

-generative organic carbon: $\mathrm{GOC}=\mathrm{HI}_{0} / 1,200$, where 1,200 is the maximum hydrogen index value corresponding with the total organic carbon;

•the initial hydrogen index value $\mathrm{HI}_{0}=\mathrm{HI}+\mathrm{HI}[(\mathrm{Tmax}-435) / 30]-$ the empirical formula accounting for the residual generation potential $\mathrm{S}_{2}$ expense dynamics;

$\bullet\left(\mathrm{HI}=100 \bullet \mathrm{S}_{2} / \mathrm{TOC}\right)$ For $\mathrm{HC}$ generation; 435 - maximum temperature of $\mathrm{S}_{2}$ hydrocarbon yield peak at pyrolysis corresponding with liquid HC generation start:

-Initial total organic carbon value $\mathrm{TOC}_{0}=\mathrm{TOC} /(1-\mathrm{GOC})$ where $\mathrm{GOC}$ is the expended portion of organic carbon; (1-GOC) is the remaining portion of organic carbon.

- OM thermal maturity: $\mathrm{TR}=\left(\mathrm{HI}_{0}-\mathrm{HI}\right) / \mathrm{HI}_{0}$, where $\left(\mathrm{HI}_{0}-\mathrm{HI}\right)$ is the expense of the residual generation potential $\mathrm{S}_{2}$ for the $\mathrm{HC}$ generation, and $\left(\mathrm{HI}_{0}-\mathrm{HI}\right) / \mathrm{HI}_{0}$ is the fraction of organic matter potential spent for the hydrocarbon generation.

-Initial content of labile (volatile) organic carbon $\mathrm{GOC}_{0}=\mathrm{TOC}_{0} \bullet \mathrm{GOC}$;

•rock density $\mathrm{D}_{1}=2.5 \mathrm{~g} / \mathrm{cm}^{3}$ (assumed);

$\bullet$ kerogen density $\mathrm{D}_{2}=1.2 \mathrm{~g} / \mathrm{cm}^{3}$ (assumed);

$\mathrm{K}$ factor $=(0.95 / 0.85)=1.118$ (it is assumed that part of kerogen $(5 \%)$ is lost in the process of diagenesis, and the labile carbon is $95 \%$ of the kerogen mass) [7];

An adsorption model of hydrocarbon molecules in organic pores is displayed in Fig. 5.

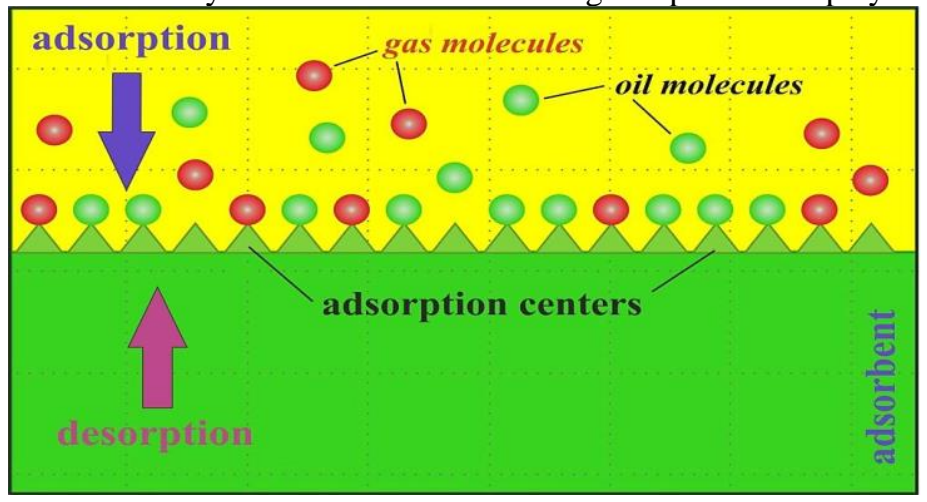

Fig. 5. The conceptual model of the adsorption of HC molecules in organic pores 
In the process of $\mathrm{OM}$ catagenesis, desorption of the generated hydrocarbons occurs in the form of hydrocarbon steam bubbles' emission with formation of shells. The shells deform the kerogen surface, which has an elevated adsorption activity, and retain any formed hydrocarbons. The pore space evolution in kerogen is running proportionally to the amount of hydrocarbons generated and emigrated during the migration period.

Organic porosity, or porosity in kerogen texture, forms in the process of OM thermal maturation. It is capable of affecting the adsorption of oil generated by the porous kerogen surface. It plays an important role in determining the total volume of the accumulated hydrocarbons in oil and gas sequences. During the OM catagenesis period, desorption of the generated hydrocarbons occurs as an emission of HC steam bubbles, which deforms the surface [9-12]. The porous surface of the kerogen has elevated adsorption activity. It retains generated hydrocarbons and contributes to the total volume of the accumulated part of hydrocarbons in oil and gas sequences. Hydrocarbon accumulation in shale sequences is a particular case of this process.

\section{Conclusion}

A study of OM geochemical parameters' specifics in the samples from wells drilled at the subject prospects allowed reviewing the causes of hydrocarbon retention capability both by the mineral matrix and by the source rock kerogen. Based on the results of the programmed pyrolysis by the Rock-Eval-6 method, an estimate has been performed of the organic (kerogen) porosity. This estimate allows determination of the forecast retention volume of $\mathrm{HC}$ generated during catagenesis. Total source rock porosity is variable, and the interrelation between HC displacement and retention processes (as characterized by $\mathrm{S}_{1} / \mathrm{TOC}$ parameter) depends on the listed factors, including the formation temperature. At shallow source rock depths, hydrocarbon emission forms a porous surface retaining components of elevated molecular mass and polarity. Detached from the kerogen surface are light and saturated HCs. After the light HCs, heavy HCs are present. Thus, a certain selectivity is taking place. Overall, the effect of oil-saturation increases with a growth of organic porosity.

This study was supported by the Ministry of Education and Science of the Russian Federation (state contract no. 10.6569.2017/BCh).

\section{References}

1. Morariu D., Aver'yanova O.YU. Neftegazovaya geologiya. Teoriya i praktika. 8, 1 (2013)

2. Lapidus, A.L., Kerimov, V.Y., Mustaev, R.N., Movsumzade, E.M., Zakharchenko, M.V. Oil Shale. 35(2), 113, (2018)

3. Guliev, I.S., Kerimov, V.Yu., and Mustaev, R.N., Doklady Earth Sci., 471, 1, 1109, (2016)

4. Kerimov, V.Yu., Osipov, A.V., Lavrenova, E.A., Neftyanoe khozyaystvo - Oil Industry, 4, 33 (2014)

5. Kerimov, V.Yu., Mustaev, R.N., Dmitrievsky, S.S., Zaitsev, V.A. Neftyanoe khozyaystvo - Oil Industry, 9, 18 (2016)

6. Kerimov, V.Y., Rachinsky, M.Z., Mustaev, R.N., Osipov, A.V. Doklady Earth Sciences, 476, 1, 1066 (2017)

7. F. Chen, Sh. Lu, and X. Ding. Hindawi Publishing Corporation Scientific World Journal. V. (2014) 
8. C. J. Modica, Scott G. Lapierre., AAPG bulletin, 96, 1, 87, (2012)

9. V.Yu. Kerimov, R.N. Mustaev, N.Sh.Yandarbiev, E.M. Movsumzade Oriental J.Chem. 33, 2, 879 (2017)

10. Mustaev, R.N., Hai, W.N., Kerimov, V.Y., Leonova, E.A. Geomodel 2015 - 17th Scientific-Practical Conference on Oil and Gas Geological Exploration and Development (2015)

11. Guliyev, I.S., Kerimov, V.Y., Osipov, A.V., Mustaev, R.N. SOCAR Proceedings, 1, 4, (2017)

12. Rachinsky, M.Z.; Kerimov, V.Y. Scrivener Publishing Wiley, 640, (2015) 